\title{
PRESENTACIÓN
}

\section{Envenenamiento infantil por plomo}

$\mathrm{E}$ ste número monográfico de Salud Pública de Mexico contiene una recopilación de trabajos originales de investigación sobre el plomo en poblaciones infantiles de diversas regiones de América Latina. Se presenta información recavada en una reunión organizada por la Organización Panamericana de la Salud en el año 2001, en Lima Perú. Los trabajos recopilados fueron realizados en Argentina, Brasil, Costa Rica, Chile, Cuba, Uruguay y en Venezuela y en ellos se discuten diferentes problemas de interés regional. Para Argentina, se presenta una revisión bibliográfica de los trabajos publicados sobre plomo en ese país y se concluye que la contaminación por plomo en la población infantil constituye un problema importante que debe ser considerado y para el cual se requiere mayor información. Igualmente, los investigadores brasileños hacen una revisión de la literatura publicada sobre este problema en su país y reportan como fuente importante de plomo las actividades relacionadas con el reciclamiento de baterías de vehículos automotores. El trabajo elaborado por Sánchez Molina y colaboradores, en relación con los patrones de descensos de plomo sanguíneo de la población costarricense, resulta sumamente interesante. Estos autores nos presentan información sobre población adulta expuesta y no a plomo, ya sea porque están expuestas a un alto tráfico vehicular o por actividades industriales relacionadas con la fabricación de baterías; además se incluyen datos sobre población infantil. Los hallazgos reportados son importantes, ya que muestran el gran impacto que ha tenido en este país la eliminación del plomo de las gasolinas. Para la población adulta se documentó una disminución de casi $15 \mu \mathrm{g} / \mathrm{dl}$ en un lapso de 10 años. Para la población pediátrica se reporta un efecto similar, aunque no de la misma magnitud. En esta población -niños de 3 a 11 años de edad-se muestra un decremento de $3 \mu \mathrm{g} / \mathrm{dl}$. En contraste, en la población ocupacionalmente expuesta no se observaron cambios, y para ella se reportaron concentracio- nes de plomo en sangre de $59 \mu \mathrm{g} / \mathrm{dl}$. García Medina y colaboradores presentan datos sobre el plomo en agua para consumo humano en Cuba; los datos presentados reafirman las bajas concentraciones de este metal en muestras obtenidas de 310 fuentes de abastecimiento comunitario. Igualmente que el estudio costarricense, el trabajo publicado por Juan Sánchez Cortés, referente a las poblaciones chilenas, muestra también una disminución importante de la concentración de plomo en sangre relacionada con la disminución de plomo en las gasolinas. Los investigadores documentan que la prevalencia de plomo en la sangre elevada (definida como $\geq$ a $10 \mu \mathrm{g} / \mathrm{dl}$ ), disminuyó de $14.5 \%$ a $1.3 \%$. En contraste, los datos presentados para Uruguay y Venezuela sugieren que la fuente más importante en estos países es la gasolina con plomo. Los promedios de plomo en sangre para la población uruguaya son altos, la media reportada es alrededor de $13 \mu \mathrm{g} / \mathrm{dl}$ lo cual se encuentra por arriba del valor recomendado de $10 \mu \mathrm{g} / \mathrm{dl}$. Igualmente, los valores reportados para las mujeres en estado de gravidez son también elevados, con una proporción importante de mujeres con valores por arriba de $10 \mu \mathrm{g} /$ dl. En el estudio de Mújica y colaboradores (Venezuela) se presentan datos de población adulta (192 hombres y 59 mujeres) que fueron reclutados de diferentes bancos de sangre en la ciudad de Caracas. El promedio del metal en sangre documentado en la población estudiada fue de $12.5 \mu \mathrm{g} / \mathrm{dl}$, lo cual también está por arriba del recomendado por la Organización Mundial de la Salud. Esto dos últimos estudios nos indican el potencial benéfico que podría tener en estos países eliminar el plomo de la gasolina, sin duda, una de las acciones de salud pública pendientes de llevar a cabo.

Los trabajos que se presentan en este volumen de Salud Pública de México también incluyen estudios originales realizados por diferentes investigadores. El trabajo sobre isótopos de plomo, de Chaudhary-Webb y colaboradores, reafirma la importante contribución 
que tiene en México la cerámica vidriada como una fuente de exposición a plomo. Esta fuente también queda evidente en el trabajo que presentan Meneses-González y colaboradores. En este trabajo, hecho en la ciudad de Cuernavaca, Morelos, en 232 niños, se documentó una media geométrica de plomo en sangre de $6 \mu \mathrm{g} / \mathrm{dl}$. El hallazgo más importante se refiere a la asociación entre los niveles elevados de plomo en sangre y el consumo en ollas de barro vidriado. El preparar y/o consumir alimentos en ollas de barro vidriado se asoció con un exceso de $2 \mu \mathrm{g} / \mathrm{dl}$ en las concentraciones de plomo en sangre. Este resultado, al igual que el trabajo antes mencionado, indica la urgencia de controlar este metal en la fabricación de piezas de alfarería rústica vidriadas a baja temperatura.

Se incluye también un trabajo sobre las series históricas del plomo en la atmósfera de la zona metropolitana de la Ciudad de México, de Cortés-Lugo y colaboradores. Este trabajo es interesante desde el punto de vista histórico, ya que presenta de manera clara el impacto que ha tenido en la concentración de plomo en el aire de la Ciudad de México la eliminación de plomo de las gasolinas.

Destaca en este volumen el trabajo realizado por Espinosa y colaboradores en Lima y El Callao, en Perú. En este trabajo se reporta la exposición ambiental de los niños de la zona metropolitana de Lima, y se documenta cómo el plomo en la gasolina puede ser una fuente importante. Sin embargo, este trabajo hace evidente la importancia de las fuentes fijas de contaminación.

Con la presentación de este volumen, Salud Pública de México pretende contribuir al control de este importante problema. El plomo continúa siendo una barrera para el desarrollo pleno de los niños de esta Región. Al disminuir sus capacidades intelectuales, el plomo disminuye las capacidades de desarrollo de la población infantil. Desafortunadamente, también la exposición a plomo se da de manera inequitativa siendo las poblaciones más desfavorecidas las que enfrentan la exposición más intensa a este metal, como se puede documentar también en los trabajos que se han presentado en este número monográfico. Aunado a otros problemas que enfrentan los niños en condiciones de pobreza, el plomo viene agravar su situación.

Esperamos que este trabajo sea de interés para los lectores de Salud Pública de México y sirva para estimular la discusión sobre la agenda pendiente que tenemos en el control de esta importante fuente de intoxicación.
Isabelle Romieu, *

* Editores Invitados 